\title{
Thermal Performance of Nomex-910 and TUK Insulating Papers in Soya- based Natural Ester Oil
}

\author{
Ankit Chouhan, Raj Kumar Jarial, and U. Mohan Rao \\ Department of Electrical Engineering, National Institute of Technology, Hamirpur, HP India, 177005. \\ Department of Applied Sciences, University of Quebec at Chicoutimi, QC, Canada. \\ mohan.ungarala1@uqac.ca
}

\begin{abstract}
In this paper, evaluation of Nomex-910 and thermally upgraded Kraft (TUK) paper has been investigated in soya-based natural ester oil by performing accelerated thermal ageing. All the test samples have been prepared in standard oil/paper ratio in accordance with the IEEE Std. C57.154.2012 and are thermally stressed at $120^{\circ} \mathrm{C}, 150^{\circ} \mathrm{C}$ and $180^{\circ} \mathrm{C}$ as per modified ASTM D1934. Diagnostic measurements those including dielectric strength and tensile strength for insulating papers; UV/Vis spectroscopy, Dissipation factor, and Resistivity of oil have been reported as per ASTM standard test methods. The degree of concentration of conductive contaminants in Nomex system is slightly higher but are comparable. This is attributable to the high absorbance of Natural ester fluid. It is found, that dielectric strength and mechanical strength of Nomex paper is superior to that of the TUK paper. The deterioration rate of paper and the oil/paper insulation system has been verified with the natural ester-nomex insulation system and is found to be a possible alternative.
\end{abstract}

Keywords: Natural ester oil, Nomex paper, Spectroscopy, tensile strength.

\section{Introduction}

Power transformers play a preeminent role in the modern technical era and have the responsibility of reliable transmission and distribution of the electrical energy. The life of the transformer is highly attributable to the performance of the insulation system $[1,2]$. The operating characteristics of solid and liquid insulations are greatly influenced by electrical and thermal stresses [3]. These stresses accelerate the ageing mechanism and consequently the service life of the insulating material gets reduced. The insulating materials become thermally unstable at elevated temperatures and lose many of their insulating properties. The rate of degradation of insulation depends on various factors such as moisture content, acid content, amount of oxygen and temperature [4]. Hydrolysis, Oxidation and Pyrolysis are the three main contributors to the degradation of insulating materials [5]. From the last several decades, numerous researchers have reported the performance of alternative insulating materials and their effect on transformer insulating materials with thermal and electrical stressing [6-15]. Cellulose based Kraft papers have been used as solid insulation in liquid filled power transformers from many decades [16]. Though the thermal class of the Kraft paper is low, it has been used by electrical utilities because of its low cost and reasonably good performance [17-18]. From the past few years, DuPont has introduced Nomex-910 electrical insulating papers which is comprised of both cellulose and aramid ingredients. It was developed to provide interlayer insulation and also used for conductor insulation in any transformer. It has a thermal class of $130^{\circ} \mathrm{C}$ in mineral oil and $140^{\circ} \mathrm{C}$ in ester oil [19]. Though Nomex insulating papers have higher thermal class than TUK paper, very less research work has been reported related to these materials [20].

TUK paper and mineral oil are the two solid and liquid insulations which have been used from many decades. At high temperatures, the cellulose paper exerts and loses many of its properties. Mineral oil filled transformers also requires additional fire safety measures and is not eco-friendly. Though, the combination works meticulously in spite of shortcomings in their electrical, thermal and mechanical properties, but there is still a need to find a better combination

Received: August $20^{\text {th }}, 2019$. Accepted: March $12^{\text {nd }}, 2020$

DOI: $10.15676 /$ ijeei.2020.12.1.5 
of solid and liquid insulations which should be environmental friendly and can enact proficiently than the existing insulations. Since performance of TUK and Nomex paper in natural ester oil is not disclosed yet, so in the present work two combinations i.e. TUK-ester and Nomex-ester have been considered for the present experimental investigation.

\section{Experimental Investigation}

A. Preparation of Samples

A large number of test samples have been prepared in the present experimental evaluation. Initially, all the conical flasks were rinsed with clean water and then dried out in air circulated oven by setting it to $100^{\circ} \mathrm{C}$ for 24 hours. This is done to remove all the moisture content which may be present in the flasks. Each flask was allowed to cool down to room temperature and then filled with natural ester oil. Oil filled flasks were again placed in the oven to ensure the complete removal of moisture content which may get added during the sample preparation. Dried TUK and Nomex papers were put separately in the oil filled flasks. Copper strip is also added to the flasks to simulate real operating conditions of the transformer. All the samples have been prepared in standard mass ratio in accordance with IEEE Std. C57.154.2012 [21]. Table 1 shows the specifications of the materials used in the experimental analysis.

Table 1. Details of materials used

\begin{tabular}{|l|l|}
\hline Material & Specifications \\
\hline Insulating Oil & Soya based Natural Ester Dielectric Fluid \\
\hline Insulating Paper & $\begin{array}{l}\text { Nomex-910 paper (3 mil) and Thermally Upgraded Kraft paper (3 } \\
\text { mil) }\end{array}$ \\
\hline Borosil Conical Flask & $250 \mathrm{ml}$ \\
\hline Electric Oven & PID based temperature controlled oven, $500 \pm 2^{0} \mathrm{C}$ \\
\hline Copper Strip & $35 \mathrm{~mm} \times 20 \mathrm{~mm} \times 3 \mathrm{~mm}$ \\
\hline Cork & Rubber \\
\hline
\end{tabular}

\section{B. Thermal Ageing Procedure}

According to IEEE Std. C57.100-2011 and IEC 60216-1:2013, only thermal stress is considered in the present experimental investigation work [22-23]. Accelerated thermal ageing has been performed on each prepared sample at $120^{\circ} \mathrm{C}, 150^{\circ} \mathrm{C}$ and $180^{\circ} \mathrm{C}$ for 48,72 and 96 hours of ageing respectively. In order to obtain the considerable changes in the dielectric properties of the insulating materials, 24 hours of ageing duration is not considered. Initially, three samples of each Nomex and TUK paper in ester oil were taken and put inside the oven whose temperature was set at $120^{\circ} \mathrm{C}$. After 48 hours of ageing, one sample of each paper was taken out from the oven and was allowed to cool down to room temperature. After that, both the samples were placed inside a dark room and handled in accordance with ASTM D923-15 [24]. Same procedure was followed after 72 and 96 hours of ageing. Now, there were three set of two samples obtained at $120^{\circ} \mathrm{C}$ after 48,72 and 96 hours. Subsequently, diagnostic tests were performed on the obtained aged samples. Similar procedure was followed for obtaining aged samples at $150^{\circ} \mathrm{C}$ and $180^{\circ} \mathrm{C}$.

\section{Results and Discussions}

\section{A. Dielectric Strength of paper}

In designing an electrical apparatus, dielectric strength of the insulating paper serves as a great deciding factor in which it is to be used. This test determines the maximum voltage which can be applied across the thickness of the insulating paper before its failure. Mineral oil was used as a surrounding medium, which meets the specification of ASTM D3487 [25]. The quality of the surrounding medium has a noticeable effect on the test results. Any significant reduction in the BDV indicates the presence of moisture in the paper. This test was conducted in accordance 
with ASTM D149-09 [26]. It is already known that the thermal class of Nomex paper in natural ester oil is more when compared with TUK paper.

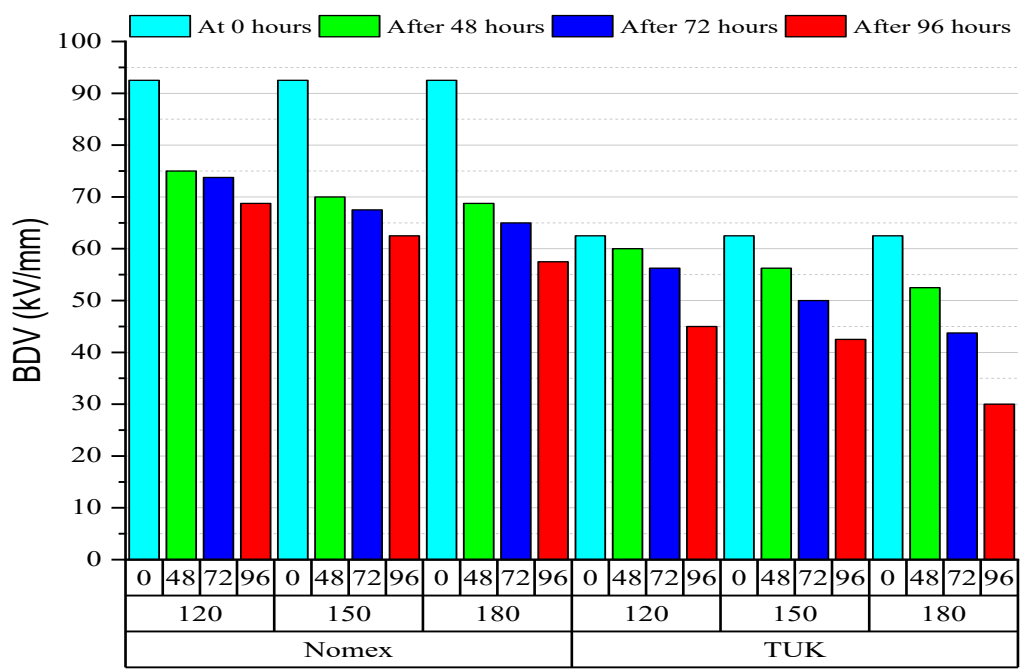

Figure 1. Variation in BDV of Nomex and TUK paper with accelerated thermal ageing.

It is observed from Figure 1 that the BDV of TUK paper sample falls down by more than $30 \%$ when the thermal stress ranges from $120^{\circ} \mathrm{C}$ to $150^{\circ} \mathrm{C}$. At $180^{\circ} \mathrm{C}$ after 96 hours, the BDV value falls down by $52 \%$ from its virgin sample value. But in case of Nomex paper, the drops in BDV value are less and it is $37.83 \%$ at $180^{\circ} \mathrm{C}$ after 96 hours. Since Nomex paper is comprised of both cellulose and aramid ingredients, it exhibits better dielectric strength than TUK paper. It is found that, for same temperature and ageing duration, Nomex paper is more thermally stable and is less degraded than TUK paper. The transformer with Nomex paper can be overloaded for more time and consequently, the life of paper insulation is comparatively better than with TUK paper.

\section{B. Tensile strength of paper}

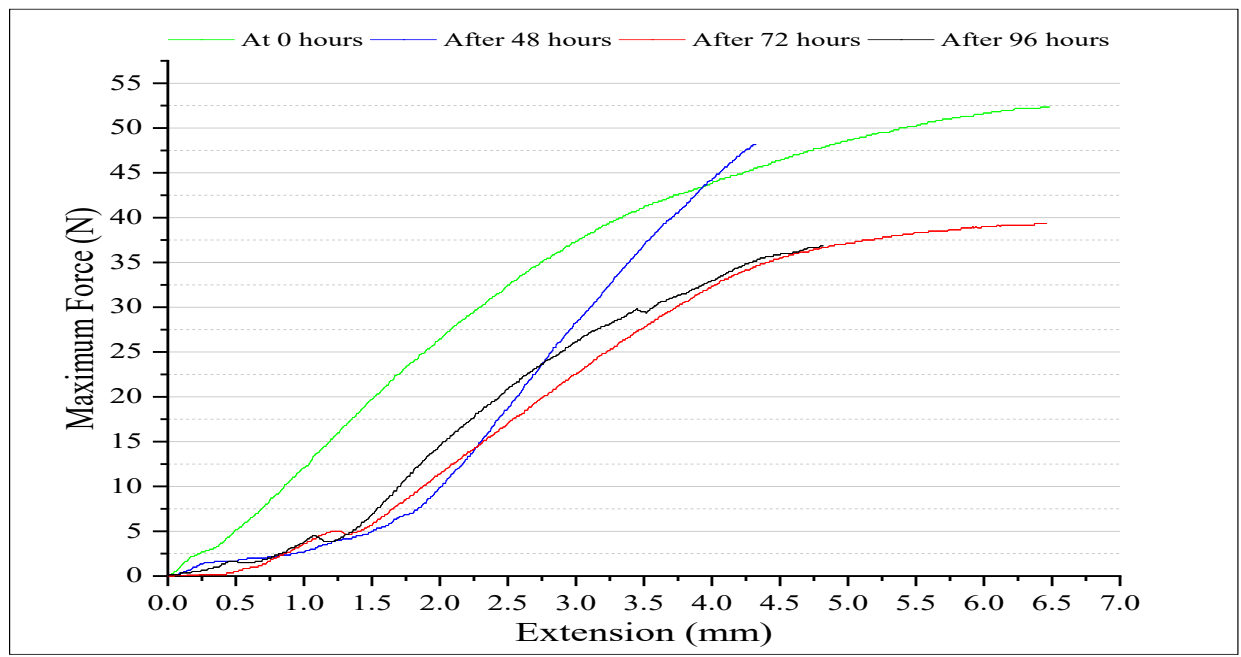

Figure 2. Tensile strength test result of Nomex paper at $120^{\circ} \mathrm{C}$. 
Tensile strength is indicative of serviceability of papers. During the wrapping of paper over the winding coils, the paper should be capable to bear the tensile force exerted on it. It determines the maximum amount of tensile stress that a material can take before failure. Degree of polymerization (DP) value and tensile strength of paper has a strong correlational with each other. With increase in ageing duration and stresses, the tensile strength of paper decreases. As the ageing of insulating paper is an irreversible process, the determination of tensile strength is very essential. Because a sudden short circuit in the winding conductors due to tearing and bursting of paper can cause catastrophic failure of the transformer. This test was conducted on Universal Testing Machine in accordance with ASTM D828-16 [27].

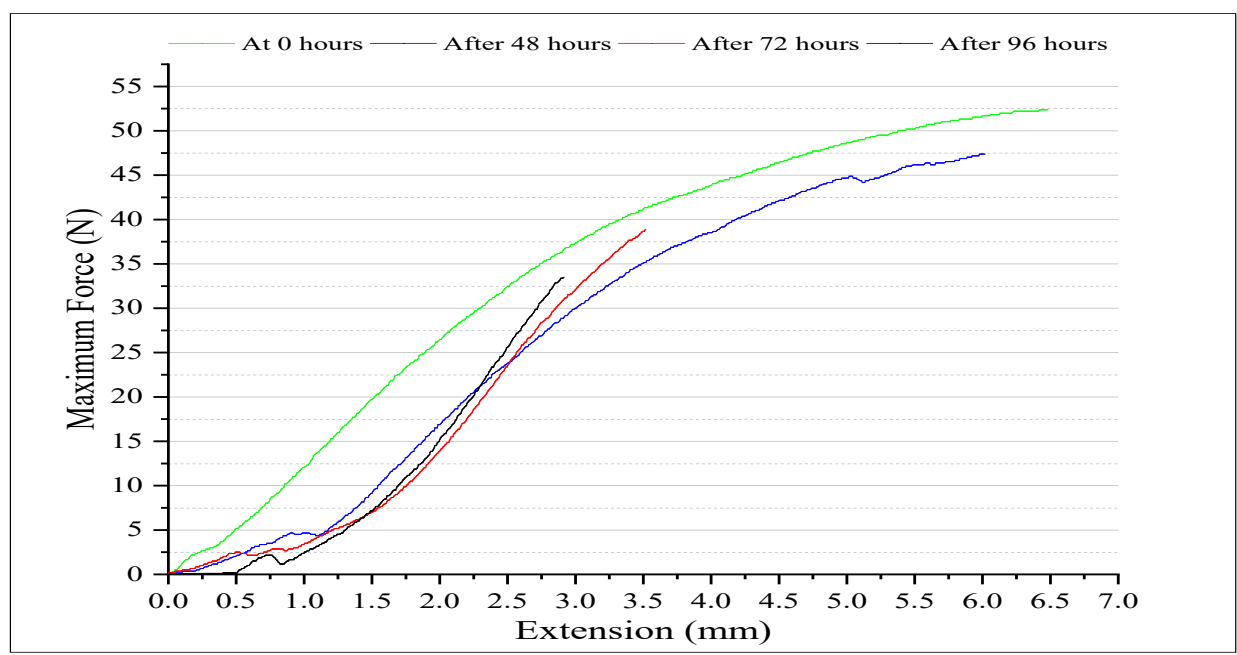

Figure 3. Tensile strength test result of Nomex paper at $150^{\circ} \mathrm{C}$.

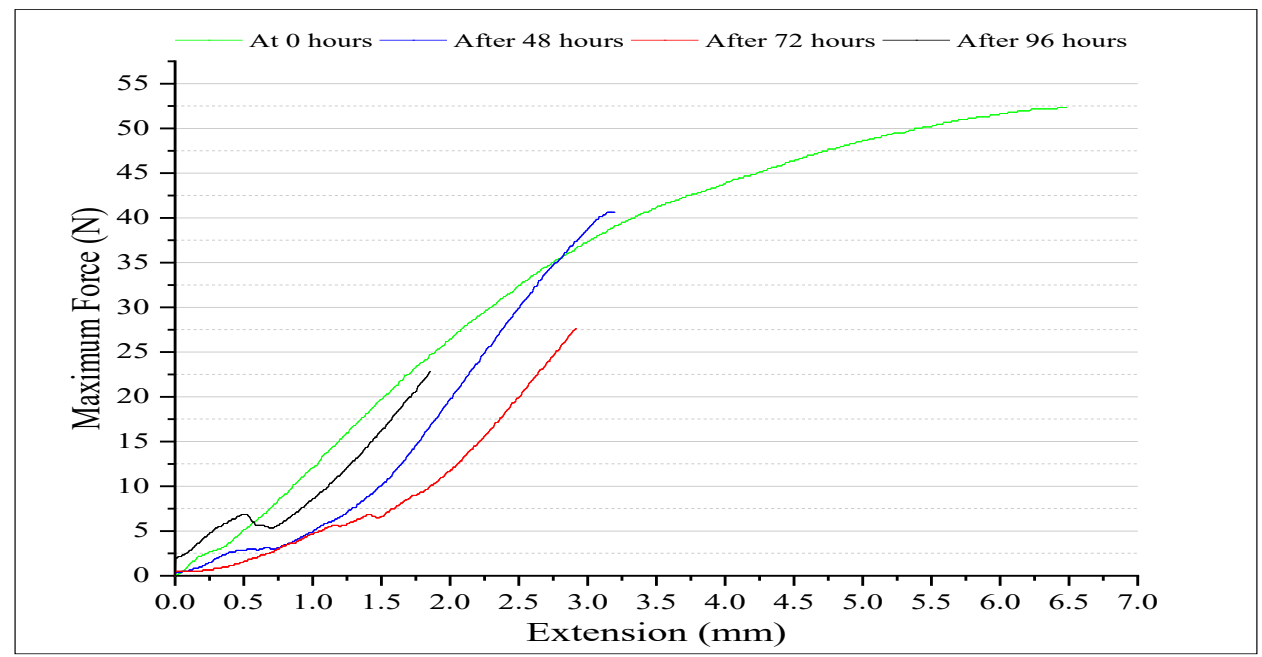

Figure 4. Tensile strength test result of Nomex paper at $180^{\circ} \mathrm{C}$.

Figure 2-4 shows tensile strength test results of Nomex paper at different temperatures and ageing durations. It can be seen that, virgin paper sample takes maximum $52.35 \mathrm{~N}$ of tensile force before failure. As the paper sample ages, the value decreases and drops to $36.85 \mathrm{~N}$ after 96 hours of ageing at $120^{\circ} \mathrm{C}$. The drops in tensile force are very high at $150^{\circ} \mathrm{C}$ and it reaches 22.85 $\mathrm{N}$ at $180^{\circ} \mathrm{C}$ after 96 hours. 


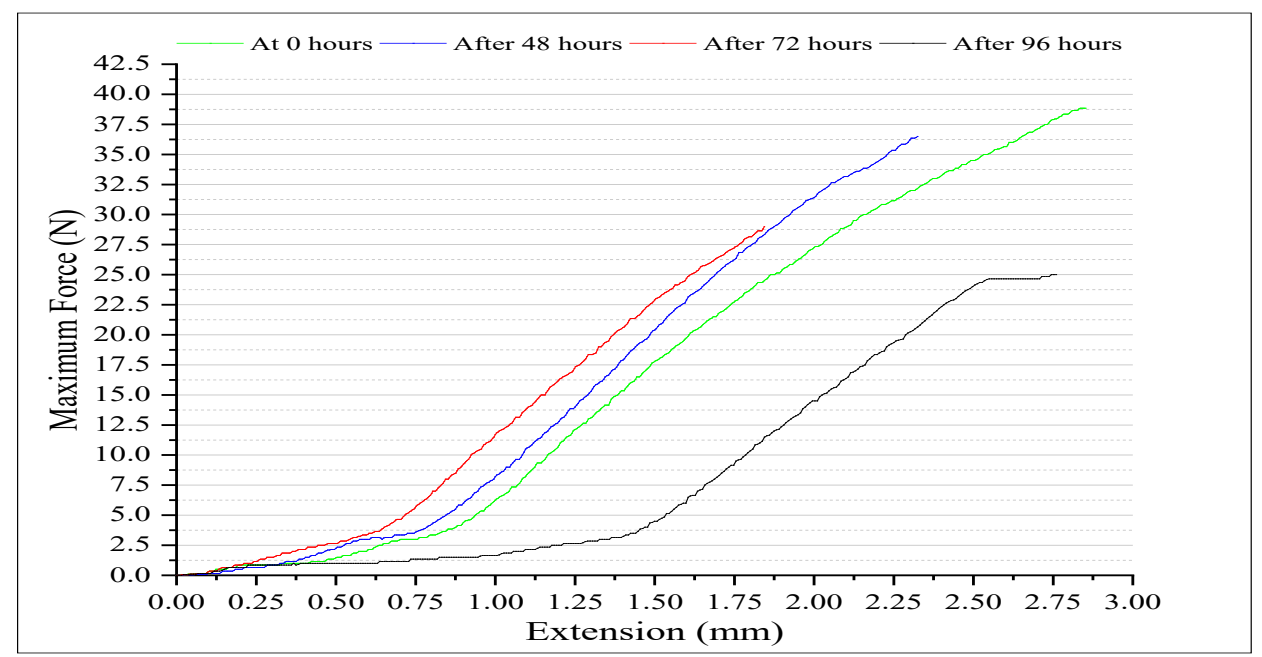

Figure 5. Tensile strength test result of TUK paper at $120^{\circ} \mathrm{C}$.

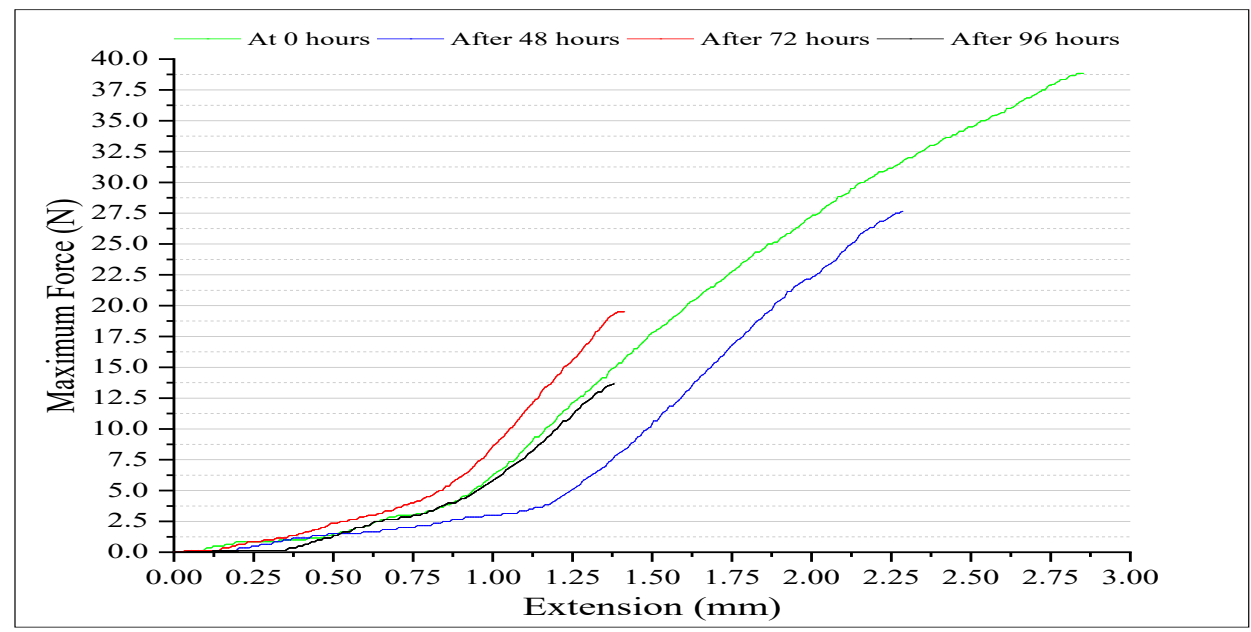

Figure 6. Tensile strength test result of TUK paper at $150^{\circ} \mathrm{C}$.

Figure 5-7 shows tensile strength test results of TUK paper at different temperatures. The virgin TUK sample takes $38.85 \mathrm{~N}$ of tensile force before failure. The maximum tensile force falls down to $25 \mathrm{~N}$ after 96 hours of ageing at $120^{\circ} \mathrm{C}$. The value drastically reduced to $6.65 \mathrm{~N}$ at $180^{\circ} \mathrm{C}$. It is found that TUK paper starts breaking at very low value of tensile force at high temperatures. It is also found that the extension range in case of Nomex paper is high which indicates that the elongation of Nomex paper is comparatively more than that of TUK paper.

Figure 8 shows the variation in tensile strength of Nomex and TUK papers. At $120^{\circ} \mathrm{C}$, the tensile strength of TUK paper sample falls down by $35.68 \%$. This value further drop to $55.35 \%$ at $150^{\circ} \mathrm{C}$ and it is highest at $180^{\circ} \mathrm{C}$. Tensile strength of TUK paper falls down drastically by $82.88 \%$ at $180^{\circ} \mathrm{C}$. For Nomex paper, the tensile strength falls down by $29.59 \%$ and $36 \%$ at $120^{\circ} \mathrm{C}$ and $150^{\circ} \mathrm{C}$ respectively which is comparatively less than TUK paper. The value falls down by $56.33 \%$ at $180^{\circ} \mathrm{C}$ after 96 hours. It is found that Nomex paper has more tensile strength and can withstand high thermal stresses for long durations. Consequently, the DP value is also less 
affected. Nomex paper is found to be more suitable for high temperature applications where high mechanical strength is desirable.

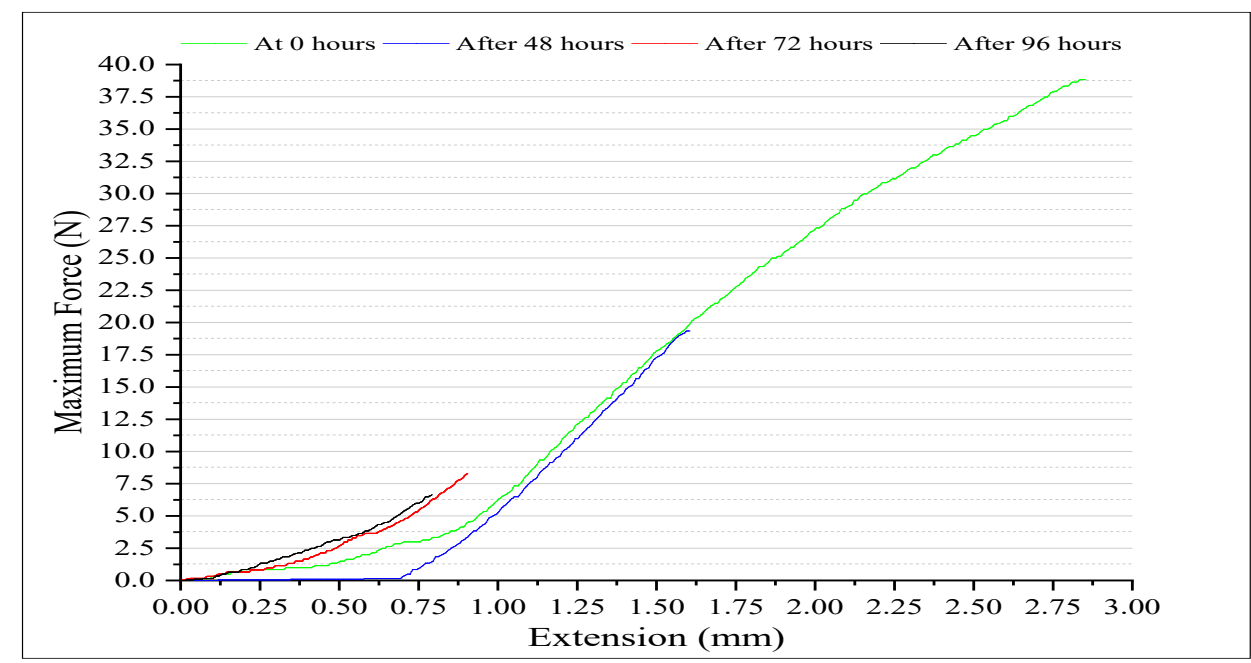

Figure 7. Tensile strength test result of TUK paper at $180^{\circ} \mathrm{C}$.

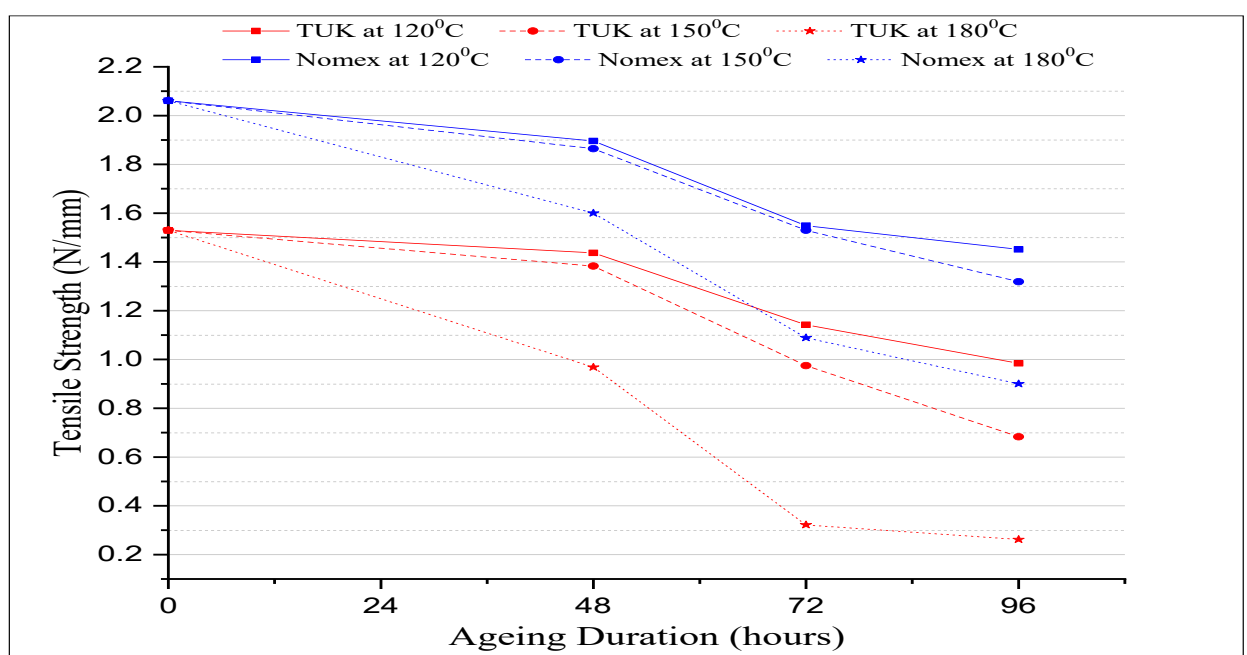

Figure 8. Variation in tensile strength of Nomex and TUK paper with accelerated thermal ageing.

\section{UV/Vis Spectroscopy of oil}

This test measures the amount of light absorbed by the oil sample due to the presence of dissolved decay products. The dissolved decay products in insulating oil contain variety of chemical compounds such as ketones, organic acids, peroxides and aldehydes. These compounds get partially adsorbed on the considerable surface of insulating paper which results in premature ageing of the power transformers. Therefore relative determination of by-product formation can be used as an important indicator of the insulating oil ageing. This test was conducted in accordance with ASTM D6802-02 [28] and sampling of oil was done with ASTM D923 [24]. 


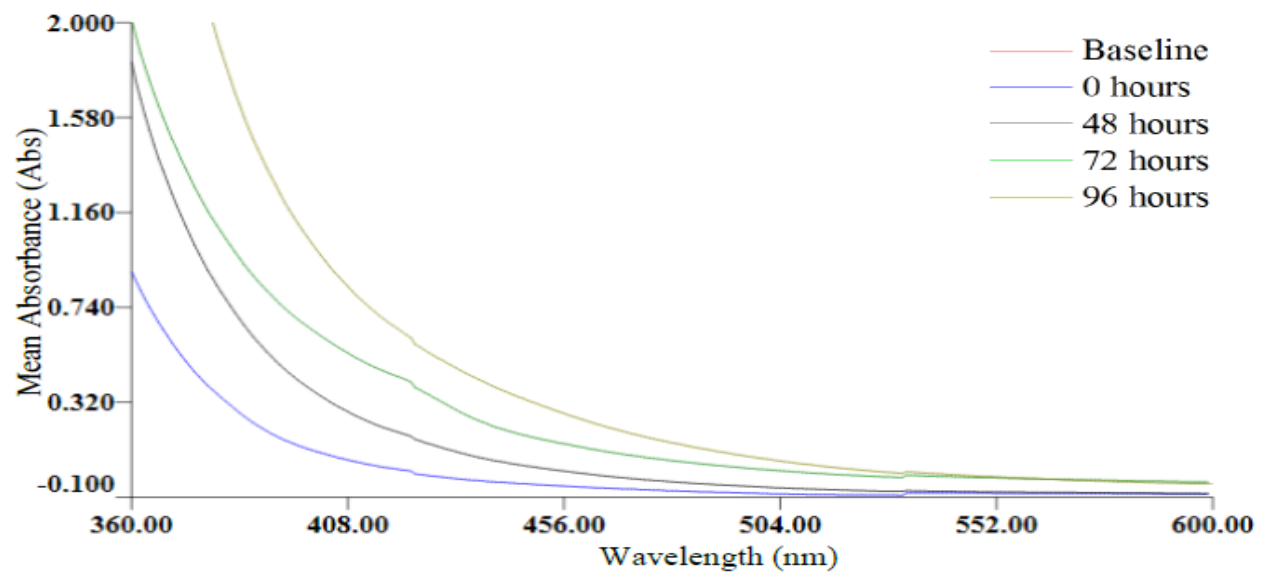

Figure 9. Variation in absorbance curve of Nomex oil sample with increase in ageing duration at $120^{\circ} \mathrm{C}$.

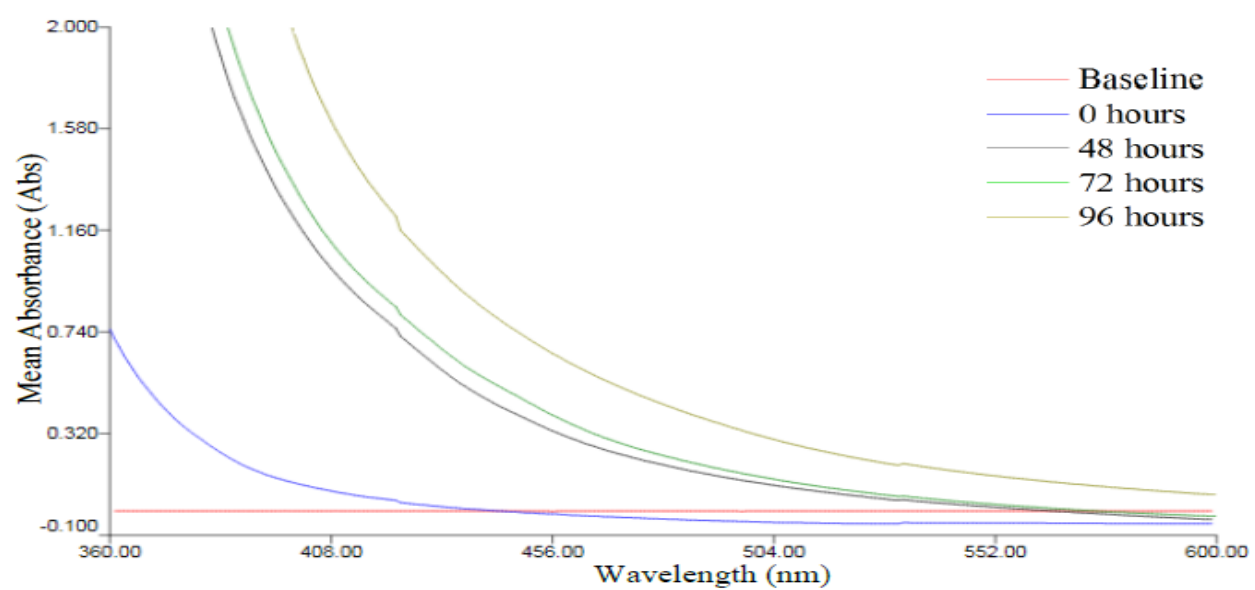

Figure 10. Variation in absorbance curve of Nomex oil sample with increase in ageing duration at $150^{\circ} \mathrm{C}$.

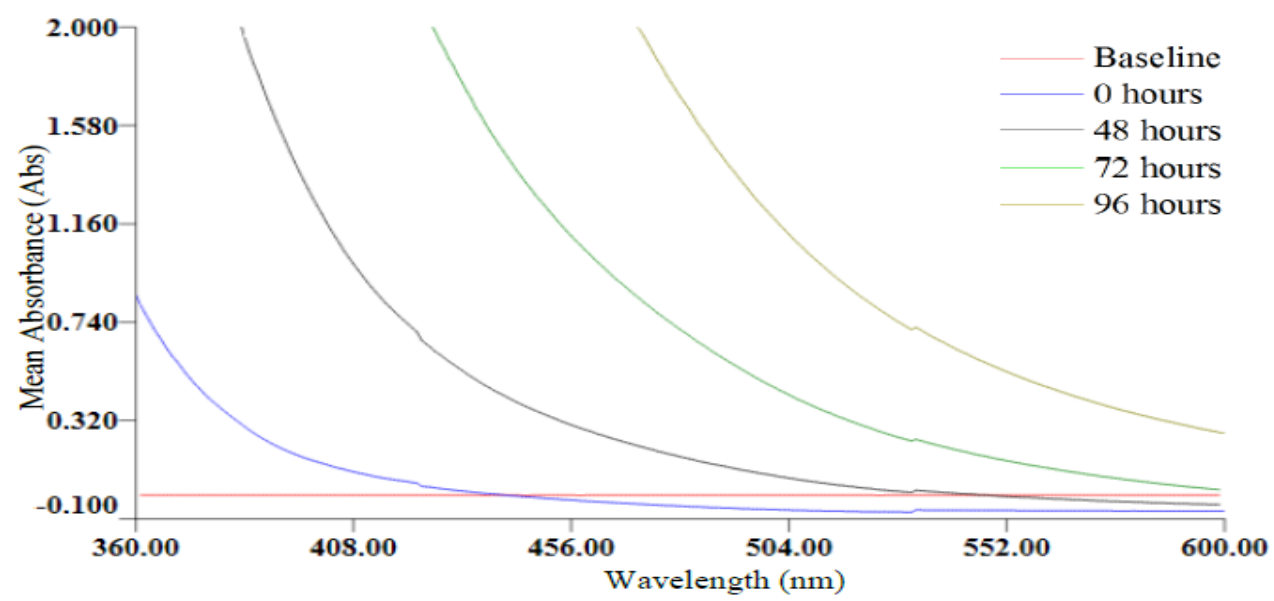

Figure 11. Variation in absorbance curve of Nomex oil sample with increase in ageing duration at $180^{\circ} \mathrm{C}$. 


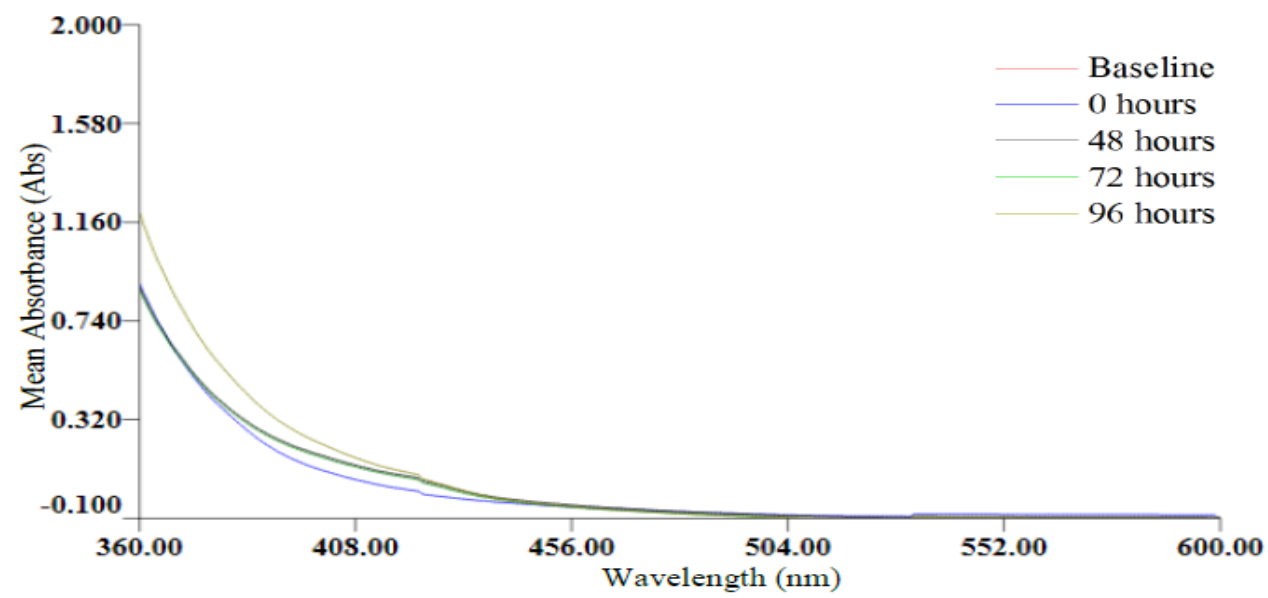

Figure 12. Variation in absorbance curve of TUK oil sample with increase in ageing duration at $120^{\circ} \mathrm{C}$.

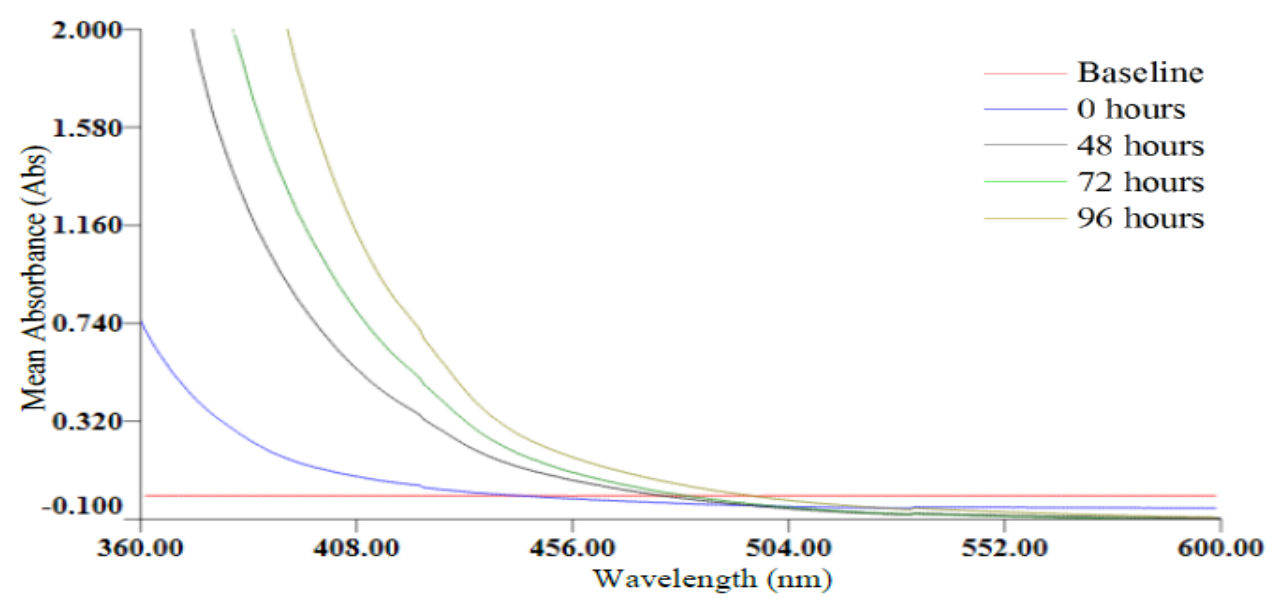

Figure 13. Variation in absorbance curve of TUK oil sample with increase in ageing duration at $150^{\circ} \mathrm{C}$.

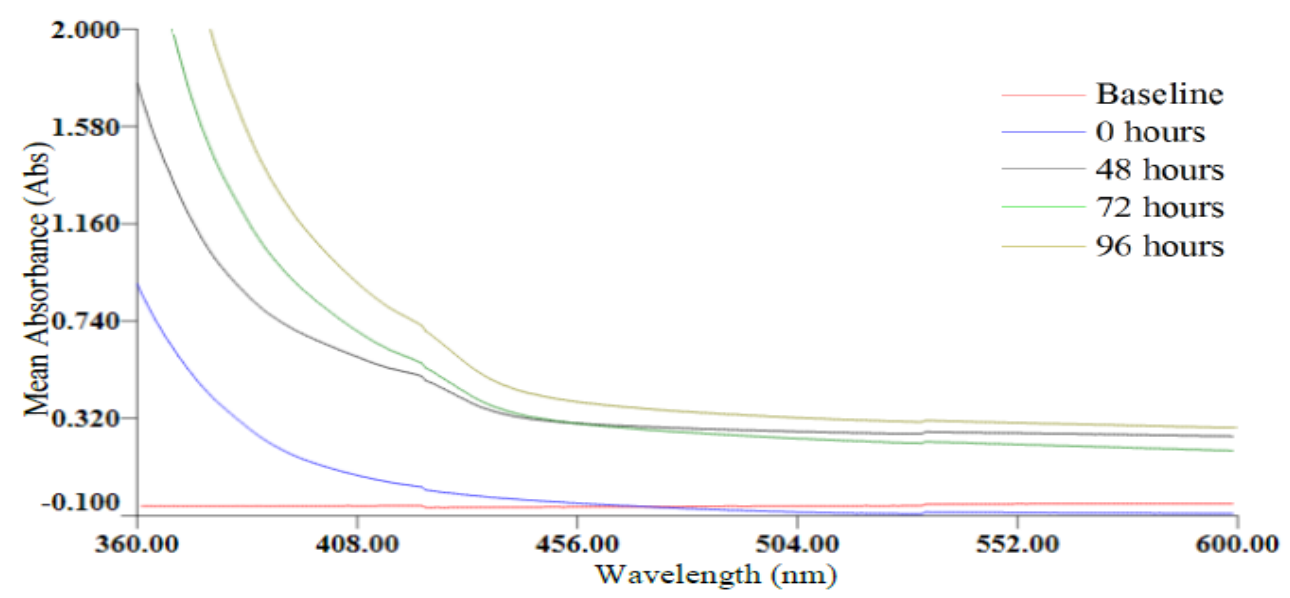

Figure 14. Variation in absorbance curve of TUK oil sample with increase in ageing duration at $180^{\circ} \mathrm{C}$. 


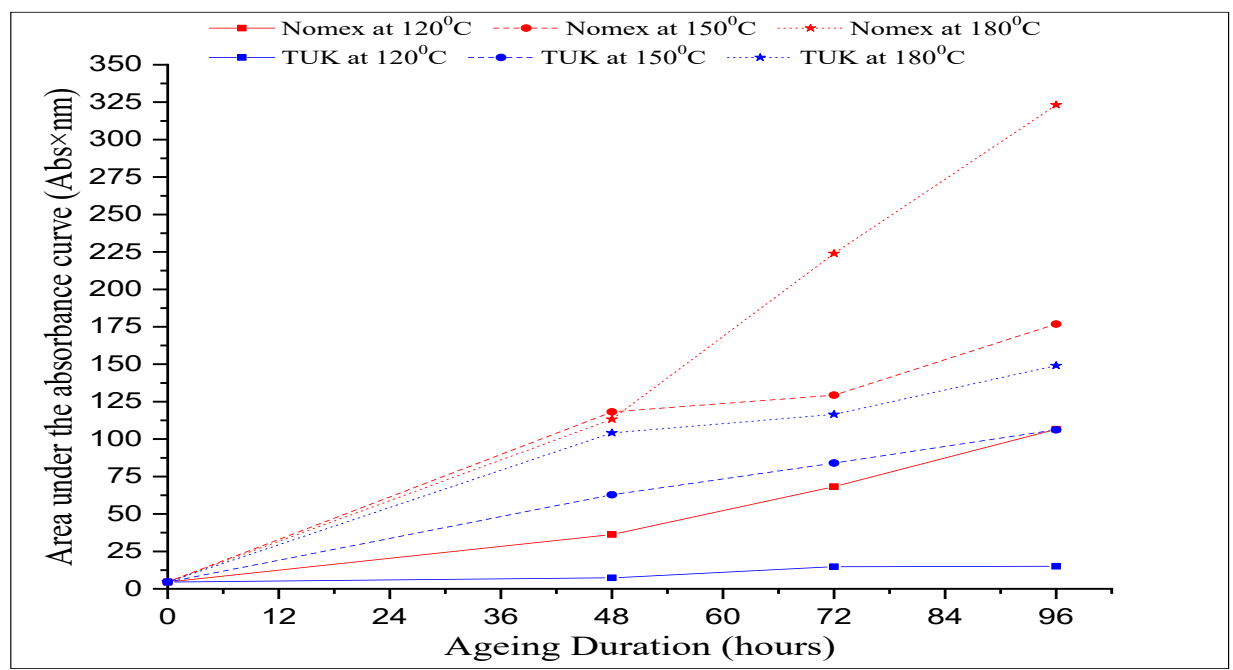

Figure 15. Variation in area under the absorbance curve of Nomex and TUK oil samples with accelerated thermal ageing.

Figure 9-14 shows the test results of UV/Vis Spectroscopy of Nomex and TUK oil samples at different temperatures and ageing durations. It can be seen that the absorbance curve shift upwards at lower wavelengths with increase in ageing duration and temperature. More shifts indicate presence of more dissolved decay contents in oil. The area under the absorbance curve has a strong relationship with the amount of dissolved decay content in oil.

From figure 15, it is found that UV spectra of TUK oil samples occupied less area under the absorbance curve than that of Nomex samples. Significant variations in absorbance curve were observed at temperature above $150^{\circ} \mathrm{C}$. At high temperatures, the Nomex impregnated oil sample struggles in its purpose and shows less oxidation stability than that of TUK sample. Though the thermal class of Nomex paper in natural ester oil is more when compared with TUK paper in natural ester oil, but Nomex paper is giving more dissolved decay products in ester oil and this may also affect the cooling performance of the oil. The absorption coefficient of Nomex test samples is found to be more than TUK test samples. This indicates that the sludge formation due to oxidation and acid formation due to thermal stress is more in Nomex test samples. This dissolved decay products also affects the dissipation factor and resistivity of the insulating oil.

\section{Dissipation factor of oil}

Dissipation factor of an insulating material serves as a great influencing factor when the material is exposed to high thermal stresses. It is indicative of the dielectric losses in insulating oil when used in an alternating field. It is also indicative of the changes in the quality of the insulating material resulting from degradation of insulation in service. Presence of small amount of moisture in oil can greatly influence the value of dissipation factor.

A good insulating oil has dissipation factor below 0.005 . This test was conducted in accordance with ASTM D924-15 [29]. Figure 16 shows variation in dissipation factor of Nomex and TUK oil samples at different temperatures for 96 hours of ageing. Dissipation factor for virgin oil sample is found to be 0.00625 and it increases with increase in temperature and ageing duration. It is found from the test results that the Nomex impregnated oil sample has very high dissipation factor which indicates high dielectric losses in oil and therefore the amount of energy dissipated as heat is also more. In case of TUK impregnated oil sample, the variation in dissipation factor is very less which indicates that the quality of TUK oil sample is good and it is not degraded much by accelerated thermal ageing. 


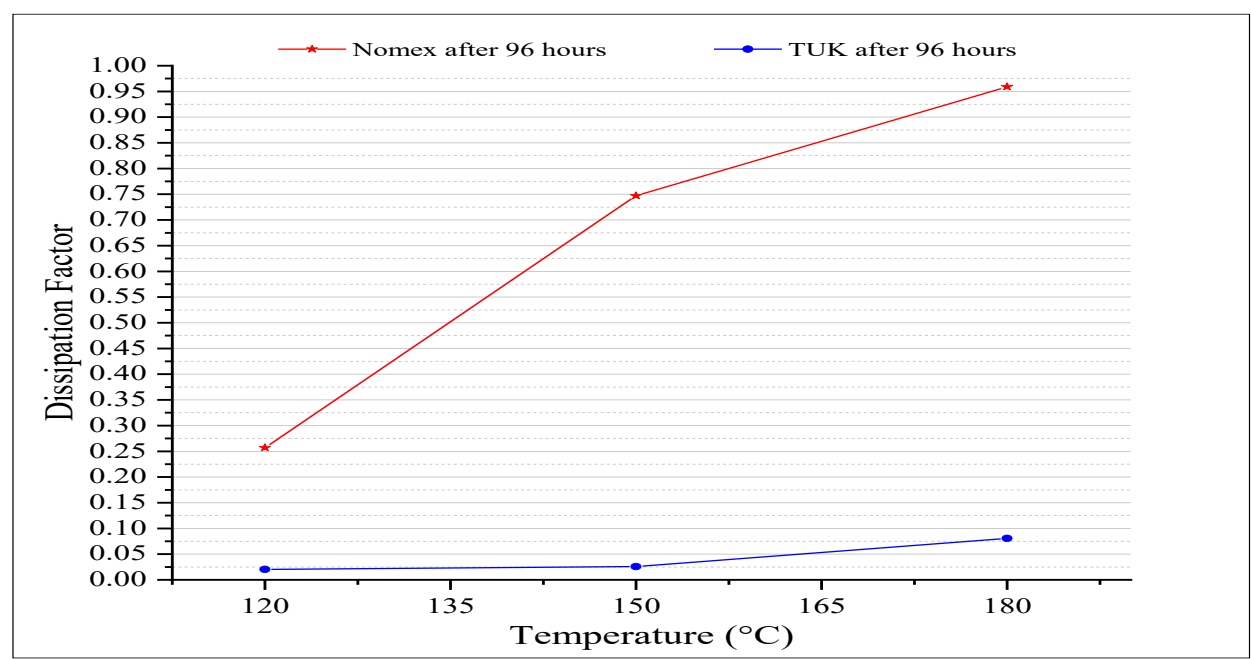

Figure 16. Variation in dissipation factor of Nomex and TUK oil sample with accelerated thermal ageing.

\section{E. Resistivity of oil}

Resistivity of the material is also correlated with dissipation value, and measures the electrical insulating properties of the insulating material. High value of resistivity is desirable in order to have low content of free ions and indicates low amount of conductive contaminants. This test was conducted in accordance with ASTM D1169-11 [30].

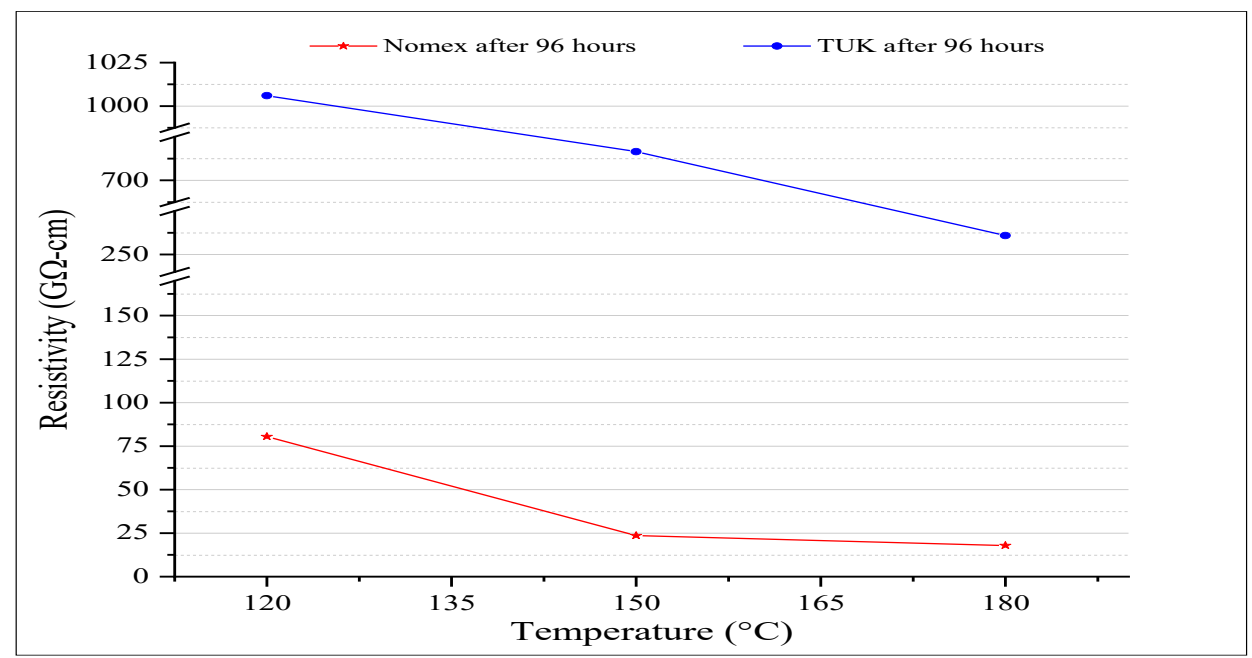

Figure 17 Variation in resistivity of Nomex and TUK oil sample with accelerated thermal ageing.

Figure 17 shows the variation in resistivity value of Nomex and TUK impregnated oil samples at different temperatures. Resistivity decreases as the insulating material ages. For virgin oil sample, the resistivity is found to be $4.769 \mathrm{~T} \Omega-\mathrm{cm}$. It is found that the Nomex paper in natural ester oil produces more amount of free ions as well as the concentration of conductive contaminants than that of TUK paper. Therefore, Nomex impregnated oil sample degrades at much faster rate when it is exposed to high temperatures for longer durations. 


\section{Conclusion}

It is found that, the BDV and tensile Strength of Nomex insulation paper is much higher than that of thermally upgraded cellulose insulation paper. But TUK paper in natural ester oil has less dissolved decay contents, low dissipation factor and high resistivity value. TUK is cellulose based, and is evident that the dielectric and mechanical strength of the TUK paper will significantly be affected or degraded at high temperatures. In TUK-Ester oil combination, the oil samples shows much better results for UV/Vis Spectroscopy, dissipation factor and resistivity test. However, rate of degradation of TUK paper is higher in natural ester fluid. Alternatively, in Nomex-Ester oil combination, deterioration of oil is higher whose properties may be regained by dehydration and other conditioning processes. Hence it is inferred that, Nomex paper in natural ester oil performs better than TUK-Ester combination and is an effective alternative for high voltage oil-paper insulation systems.

\section{References}

[1]. A. A Abdelmalik, "Analysis of Thermally Aged Insulation Paper in a Natural Ester-based Dielectric Fluid”, IEEE Trans. Dielectr. Electr. Insul., 2015, Vol. 22, No. 5, pp. 2408-2414.

[2]. C. Ranga, A. K. Chandel, "Expert System for Health Index Assessment of Power Transformers," International Journal on Electrical Engineering and Informatics Vol. 9, No. 4, pp. 850-865, 2017.

[3]. M. Mondal. G.B. Kumbhar, "Partial discharge localization in a power transformer: Methods, trends and future research," IETE Techn. Review 2016, vol. 33, pp. 1-10.

[4]. Hamdi Ahmed, I. Fofana., M. Djillali, "Stability of mineral oil and oil-ester mixtures under thermal aging and electrical discharges", IET Gener. Transm. Distrib., 2017, Vol. 11 Iss. 9, pp. 2384-2392.

[5]. D. Martin, T.K.Saha, T.Gray, K. Wyper, "Determining Water in Transformer Paper Insulation: Effect of Measuring Oil Water Activity at Two Different Locations", IEEE Electr. Insul. Mag., 2015, Vol. 31, No. 3, pp. 18-25.

[6]. M. Augusta G. Martins and A. R. Gomes, "Comparative Study of the Thermal Degradation of Synthetic and Natural Esters and Mineral Oil: Effect of Oil Type in the Thermal Degradation of Insulating Kraft Paper," IEEE Electr. Insul. Magazine, 2012, vol. 28, no. 2 , pp. 22-28.

[7]. U. Mohan Rao, H. Pulluri, N.G. Kumar, "Performance Analysis of Transformer Oil/Paper Insulation with Ester and Mixed Dielectric Fluids," IEEE Transactions on Dielectrics and Electrical Insulation, Vol. 25, No. 5, pp: 2475 - 2484, Oct 2018.

[8]. Y. Xu, S. Qian, Q. Liu and Z. D. Wang, "Oxidation Stability Assessment of a Vegetable Transformer Oil under Thermal Aging," IEEE Trans. Dielectr. Electr. Insul., 2014, vol. 21, no. 2, pp. 683-692.

[9]. U. Mohan Rao, Y. R. Sood, R. K. Jarial, "Oxidation Stability Enhancement of a blend of Mineral and Synthetic Ester oils", IEEE Electr. Insul. Mag., 2016, Vol. 32, No. 2; pp. 4347.

[10]. U. Mohan Rao, Y. N. Kumar, R. K. Jarial, "Understanding the Aging Behaviour of Transformer Oil-Paper Insulation with Ester and Mixed Dielectric Fluids," IET Science, Measurement \& Technology, Vol. 12, No. 7, pp. $851-857,2018$

[11]. O.H. Fernández, I. Fofana, J. Jalbert, S. Gagnon, Rodriguez-Celis, Duchesne, M.Ryadi, M, "Aging Characterization of Electrical Insulation Papers Impregnated with Synthetic Ester and Mineral Oil: Correlations Between Mechanical Properties, Depolymerization and Some Chemical Markers", IEEE Trans. Dielectr. Electr. Insul., 2018, Vol. 25, No. 1, pp. 217-227.

[12]. N. Yadav, R. K. Jarial, U. Mohan Rao, "Characterization of Mineral oil Based Fe3O4 Nanofluid for Application in Oil Filed Transformers," International Journal on Electrical Engineering and Informatics Vol. 10, No. 1, pp. 338-349, 2018. 
[13]. K. Bandara, C. Ekanayake and T. K. Saha, "Understanding the Ageing Aspects of Natural Ester Based Insulation liquid in Power Transformer," IEEE Trans. Dielectr. Electr. Insul., vol. 23, no. 1, pp. 246-257, 2016.

[14]. P. Verma, D. S. Chauhan and P. Singh, "Effects of Tensile Strength of Transformer Insulation Paper under Accelerated Thermal and Electrical Stress," Annual Report Conference on Electrical Insulation and Dielectric Phenomena, pp. 619-622, 2007.

[15]. Fernandez, I., Ortiz, A., Delgado, F., Renedo, C., Perez, S.: 'Comparative evaluation of alternative fluids for power transformers', Electr. Pow. Sys. Res., Elsev. Sci., 2013, Vol. 98, pp. 58-69.

[16]. R. Liao and Y. Lin, "The effects of insulating oil replacement upon power transformer condition assessment," Electr. Power Compo. Syst., vol. 43, no. 17, pp. 1971-1979, 2015.

[17]. O. W. Dennis, J. Goudie and H. A. Rojas Teran, "Surface breakdown test results of mineral oil and silicone oil with Kraft paper and Nomex," IEEE International Symposium on Electrical Insulation, pp. 254-257, 1992.

[18]. J. Jeong, J. Sik and C. S. Huh, "Accelerated ageing effects of mineral and vegetable transformer oils on medium voltage power transformers," IEEE Trans. Dielect. Electr. Insul., vol. 19, no. 1, pp. 156-161, 2012.

[19]. http://protectiontechnologies.dupont.com/Nomex-910-transformer-insulation.

[20]. B. S. Kang, M. R. Levit, R. P. Marek, R. C. Wicks and R. L. Provost, "Development of a new solid insulation for liquid-immersed transformers," Electrical Insulation Conference, Philadelphia, PA, pp. 344-347, 2014.

[21]. IEEE Standard for the Design, Testing and Application of Liquid-Immersed Distribution, Power and Regulating Transformers using High Temperature Insulation Systems and Operating at Elevated Temperatures, IEEE Std. C57.154-2012.

[22]. IEEE Standard Test Procedure for Thermal Evaluation of Insulation Systems for LiquidImmersed Distribution and Power Transformers, IEEE Std. C57.100-2011.

[23]. Electrical Insulating Materials - Thermal Endurance Properties-Part 1: Ageing Procedures and Evaluation of Test Results, IEC 60216-1:2013.

[24]. Practices for Sampling Electrical Insulating Liquids, ASTM D923-15.

[25]. Specification for Mineral Insulating Oil used in Electrical Apparatus, ASTM D3487.

[26]. Standard Test Method for Dielectric Breakdown Voltage and Dielectric Strength of Solid Insulating Materials at Commercial Power Frequencies, ASTM D149-09 (Reapproved 2013).

[27]. Standard Test Method for Tensile Properties of Paper and Paperboard using Constant-Rateof-Elongation Apparatus, ASTM D828-16.

[28]. Test Method for Determination of the Relative Content of Dissolved Decay Products in Mineral Insulating Oils by Spectrophotometry, ASTM D6802-10.

[29]. Standard Test Method for Dissipation Factor (or Power Factor) and Relative Permittivity (Dielectric Constant) of Electrical Insulating Liquids, ASTM D924-15.

[30]. Test Method for Specific Resistance (Resistivity) of Electrical Insulating Liquids, ASTM D1169-11. 


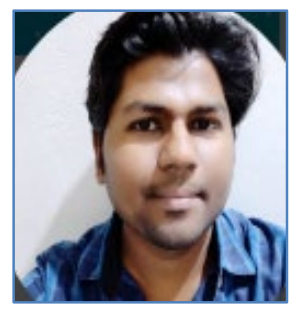

Ankit Chouhan completed his bachelors in Electrical Engineering during 2015 from G S Institute of Technology \& Science, India. Later, he finished Masters in Condition monitoring and control from National Institute of Technology Hamirpur, India in the year 2018. His research interests include dielectric oils, high voltage engineering and transformer diagnostics.

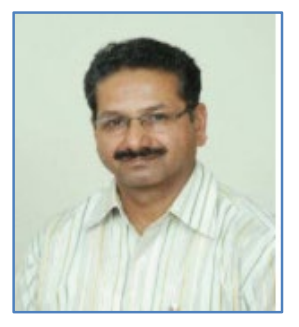

Raj Kumar Jarial (M'15). He is a member of DEIS. He received his Bachelor's degree [B. Sc. Engg. (Electrical)], and Master's degree (Power System) in 1989 and 1992 respectively from the National Institute of Technology, Kurukshetra, India. Since 1994, he has been with the department of Electrical Engineering, NIT Hamirpur India. Presently he is also the coordinator for the power transformer diagnostics center at NIT, Hamirpur, India. His current research interest includes Power Electronics based drives and High Voltage Engineering.

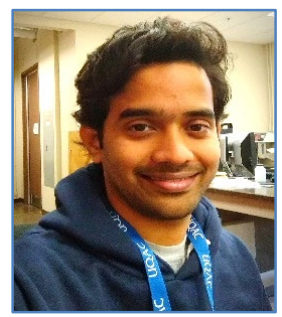

U. Mohan Rao (M'15) obtained his bachelor degree in Electrical and Electronics Engineering from Jawaharlal Nehru Technological University Kakinada, India in 2010. He obtained his master's and doctoral degrees from National Institute of Technology (NIT), Hamirpur, India in 2012 and 2017 respectively. Presently, he is a post-doctoral fellow at the Université du Québec à Chicoutimi (UQAC), Quebec, Canada with the Research Chair on the Aging of Power Network Infrastructure (ViAHT). He is a member of the IEEE DEIS and IEEE SA. Dr. Mohan is also a member of the IEEE DEIS Technical Committee on "Liquid Dielectrics" and CIGRE Canada. His main research interests include aging phenomena of high voltage insulation, condition monitoring of electrical equipment, power transformer diagnostics, and alternative liquid dielectrics. 